\title{
A Functional Analysis of Sensory Units Innervating Epiglottis and Larynx
}

\author{
Arthur T. StOREY ${ }^{1}$ \\ Departments of Physiology and Orthodontics, Uniz'ersity of Michigan, \\ Ann Arbor, Michigan
}

Received September 22; revision received October 30, 1967

\begin{abstract}
Both swallowing and coughing, protective reflexes of the airway, can be initiated from the larynx. The purpose of this study was to find the laryngeal receptors excited by the adequate stimuli for these reflexes and to define the characteristics of their discharge to the stimuli. This represents the first step in defining the significant parameters of the input for each protective reflex. The laryngeal tactile receptors appear to initiate both reflexes. These receptors are the most superficial and are probably free endings. Seventy-five per cent of the tactile receptors are also responsive to water stimulation, the adequate stimulus for swallowing. The water response of tactile units is facilitated by mechanical stimulation. The transducer sites for water stimulation are sensitive to general anesthetics while the mechanotransducer sites are not. The discharge patterns, adaptation characteristics, and duration of discharge with mechanical stimulation are dependent on the strength of mechanical stimulation. The frequency and adaptation characteristics with water stimulation are dependent on the concentration of water in the solution and not on mechanical, osmotic, or trace-calcium effects. Frequency of discharge and the pattern of units excited are hypothesized as the most significant parameters of the sensory discharge initiating the appropriate reflex.
\end{abstract}

\section{Introduction}

Protection of the airway is phylogenetically the oldest function of the larynx (25). Coughing, most easily elicited by mechanical stimulation of the larynx (37), clears the airway of aspirated foreign material. Swallowing, readily elicited by water stimulation of the larynx (34), may clear the larynx of bronchial and tracheal secretions, guard the airway from saliva and liquid bolus residues, or both. As the first step in elucidating the manner in which the appropriate protective reflex is initiated from this

1 This study was supported in part by Grant AM-07789 from the National Institute of Arthritis and Metabolic Diseases, National Institutes of Health, United States Public Health Service.

Present address: Faculty of Dentistry, University of Toronto, 124 Edward Street, Toronto 2, Canada. 
pluripotential region, the discharge patterns of laryngeal and epiglottal sensory units to a range of mechanical and chemical stimuli under various experimental conditions were examined.

\section{Methods}

Forty cats were anesthetized by cephalic vein injection of sodium amytal (Surital) $(30-50 \mathrm{mg} / \mathrm{kg})$ and then electrolytically decerebrated. Ten other cats were anesthetized by cephalic vein injection of sodium pentobarbital (Nembutal) $(30-40 \mathrm{mg} / \mathrm{kg})$ or intraperitoneal injection of alpha chloralose $(60 \mathrm{mg} / \mathrm{kg})$. Small doses of sodium amytal $(2.5-10 \mathrm{mg})$ were given intravenously to the chloralose animals before surgery and later in the experiment, if necessary, to suppress any myoclonic activity. The larynx was exposed from the ventral aspect, laid open by means of spring clips and protected from dehydration, when not recording, by thin polystyrene film. A superior laryngeal nerve (SLN) was dissected free and severed near the nodose ganglion. Strands containing several viable fibers were teased off the main trunk under liquid paraffin for single-unit recording. Action potentials were led through platinum electrodes to a multi-channel cathode-ray oscilloscope (CRO) and photographed at $100 \mathrm{~mm} / \mathrm{sec}$ with a CRO-recording camera. Force magnitudes, temperature, on-off signals, and time bases were recorded as needed on other CRO channels. Units were found by systematically applying a range of stimuli to the exposed larynx, whose salient features are identified in Fig. 1. Tactile units were excited by a brief contact of the laryngeal mucosa with a tiny ox-hair brush. The responses of some of these units were evaluated more precisely by applying known forces to the receptor. Forces of $0.01-0.32 \mathrm{~g}$ were delivered by the modified pointer of a galvanometer in series with a 1.4-V mercury battery and one of two ganged 10,000 -ohm potentiometers. The other potentiometer in series with another $1.4-\mathrm{V}$ mercury battery and one channel of the CRO made possible a concurrent recording of the stimulus force. Pressure and proprioceptive units were excited by pressure or displacement with a plastic probe $1 \mathrm{~mm}$ in diameter. Quantification of these forces was done in some cases with a pressure-sensitive stylus. Pressure applied with the stylus was monitored on one channel of the CRO connected in series with this variable resistance and a mercury battery. Mechanoreceptors were tested for responses to puffs of air delivered by an artificial respiration pump (Harvard 607) delivering $200 \mathrm{ml}$ at a frequency of $18 / \mathrm{min}$.

Thermal responses were recorded using a glass-bead thermistor (Fenwall GA 51J1) in series with a $1.4-\mathrm{V}$ mercury battery and one channel of the CRO. The thermistor was placed lightly against the mucosa overlying proprioceptors or tactile receptors and cold (20C) or hot (40C) isotonic 


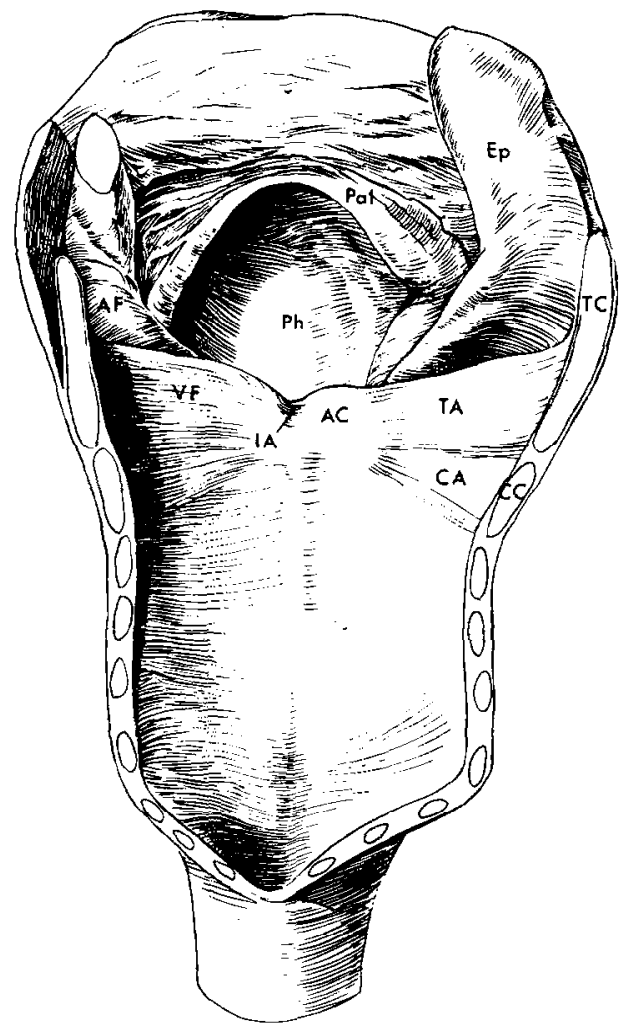

Fig. 1. Ventral view of exposed cat's larynx. Pal, palate; Ep, epiglottis; $P h$, pharynx; $\mathrm{AF}$, aryepiglottic fold; $\mathrm{VF}$, vocal fold; $\mathrm{TC}$, thyroid cartilage; $\mathrm{CC}$, cricoid cartilage; $\mathrm{AC}$, arytenoid cartilage; IA, interarytenoid muscle; $\mathrm{TA}$, thyroarytenoid muscle; CA, lateral cricoarytenoid muscle.

saline dribbled down the probe supporting the thermistor. Chemoreceptor responses were elicited by randomly dropping or flowing the test solutions or water (distilled and demineralized) over the receptor area. Test solutions included $0.005,0.01,0.02,0.05,0.1,0.2$, and $0.5 \mathrm{M}$ sodium chloride, sodium acetate, and calcium chloride in water; $0.28 \mathrm{M}$ sucrose in water, $0.5 \mathrm{M}$ sucrose in water; $0.28 \mathrm{M}$ sucrose in Ringer's, $0.5 \mathrm{M}$ sucrose in Ringer's; $0.01 \mathrm{M}$ quinine hydrochloride in Ringer's; $0.2 \mathrm{M}$ acetic acid in Ringer's; and $4.3 \mathrm{~m}$ ethanol in water. The receptive field of a unit being tested was irrigated between tests with $0.2 \mathrm{M}$ sodium chloride solution. The mammalian Ringer's solution contained $0.9 \mathrm{~g}$ sodium chloride, $0.03 \mathrm{~g}$ potassium chloride, $0.025 \mathrm{~g}$ calcium chloride, and $0.02 \mathrm{~g}$ sodium bicarbonate per $100 \mathrm{ml}$. The field size and shape of proprioceptive, tactile, and pressure units was assessed by excitation with a plastic probe or small ox-hair brush. 
Fields have been mapped for the proprioceptive and pressure units and centers of the fields for tactile and water units.

\section{Results}

Out of a total of 506 SLN units, 125 were classified as proprioceptive, 152 as tactile, 26 as pressure, and 87 as water according to the criteria of Andrew (5) for proprioceptors, Hunt and McIntyre (15) for touch and pressure receptors, and Zotterman (41) for water receptors. These four classes represented the most numerous types of units. The remaining 197 units included some which responded only during swallowing, others which discharged only to cold, and others to moving liquid. Many units showed characteristics of more than one class of unit. Fourteen units which had characteristics of both proprioceptive and tactile units (hybrid units) were found in the four cats anesthetized with alpha chloralose.

Proprioceptive Units. Seventy-six units were examined by applying pressure over a laryngeal muscle (muscle units) and 56 units by displacing the epiglottis or arytenoid, and thyroid cartilages (position units). Excitation of units by pressure required forces in excess of $0.3 \mathrm{~g}$. Six units firing to pressure also fired to displacement. Proprioceptors did not respond to puffs of air. The frequency of discharge of proprioceptive units was elevated by cold isotonic saline in eight instances, depressed in 14, and not altered in 12 cases. Hot isotonic saline elevated the frequency of discharge in three cases and did not alter the tonic discharge in the other nine cases tested. Proprioceptive units were rarely influenced by any of the test solutions except alcohol. Of 15 units tested, nine increased their frequency of firing to alcohol. No units responded to water or any of the other aqueous solutions. Proprioceptive units were usually refractory to topically applied local anesthetic.

Of the 125 proprioceptive units, 86 were tonically active, 26 were linked to respiratory movements of the larynx, and 20 were usually silent. Seven units were identified whose background discharges spontaneously shifted from one pattern to another. Silent units became phasic, and phasic units became tonic; in time both types reverted to their previous pattern. Tonic or phasic frequencies ranged from 12 to $60 \mathrm{impulse} / \mathrm{sec}$.

Pressure-induced discharges ranged from 50 to $200 \mathrm{impulse} / \mathrm{sec}$. A typical muscle unit with a tonic background discharge of 26 impulse/sec and a pressure-induced discharge of 50 impulse/sec is illustrated in Fig. $2 \mathrm{~B}$. If the stimulus force was small, tonic units resumed their original frequency when the stimulation ceased (Fig. 2B); if the force was greater the unit would fall silent for periods of up to $5 \mathrm{sec}$ when the force was removed (Fig. 2C). The duration of this silent period varied directly with the magnitude of the force (muscle units) or the amount of the deflection 

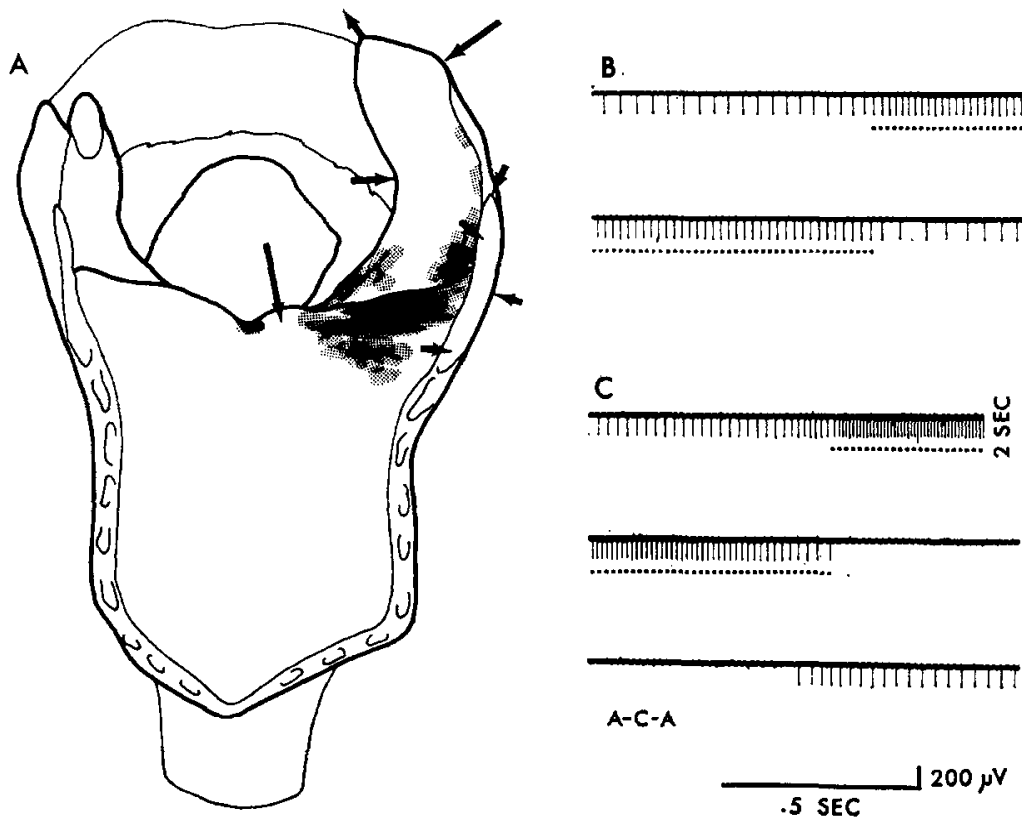

Fig. 2. Receptor fields, exciting forces and discharge patterns of proprioceptive units. A, shaded areas indicate the size and distribution of receptor fields of muscle units; arrows indicate forces which excited position units. The length of the arrows indicates the relative numbers of units excited by these various displacements, e.g., 11 units excited by displacement of the arytenoid cartilage. $B$, discharge pattern of an arytenoid position unit to slight displacement for approximately $1 \mathrm{sec}$ (indicated by the broken line). C, discharge pattern of the same unit to greater displacement for $3 \mathrm{sec}$. A silent period followed the period of stimulation. Record B is continuous: $2 \mathrm{sec}$ of the recording has been removed from $C$.

(position units). Some of the muscle units were excited by both pressure normal to the mucosa overlying the muscle and by stretching of the muscle: most would respond only to pressure. Position units usually showed an increase in frequency of discharge to deflection in one direction, and a decrease in frequency in the other direction. Displacement of the epiglottis or arytenoid cartilages would sometimes increase the frequency, sometimes decrease the frequency, or occasionally turn off the unit. The frequency of discharge in a typical position unit was $10 \mathrm{impulse} / \mathrm{sec}$, when the epiglottis was flexed $45 \mathrm{deg}$ toward the larynx, $21 \mathrm{impulse} / \mathrm{sec}$ when flexed $70 \mathrm{deg}$, and 27 impulse/sec when flexed $90 \mathrm{deg}$. The frequency of discharge is a function of the rate of application of the force as well as the magnitude of the force. The initial frequency in Fig. 3C ( $84 \mathrm{impulse} / \mathrm{sec})$ was greater than in Fig. 3B (56 impulse/sec) due to the more rapid application of the force $(12 \mathrm{~g} / \mathrm{sec}$ in $\mathrm{B}$ as compared to $40 \mathrm{~g} / \mathrm{sec}$ in C). At a constant force of $16 \mathrm{~g}$ in $\mathrm{B}$ and $\mathrm{C}$ the final frequencies were the same (64 impulse/sec). 

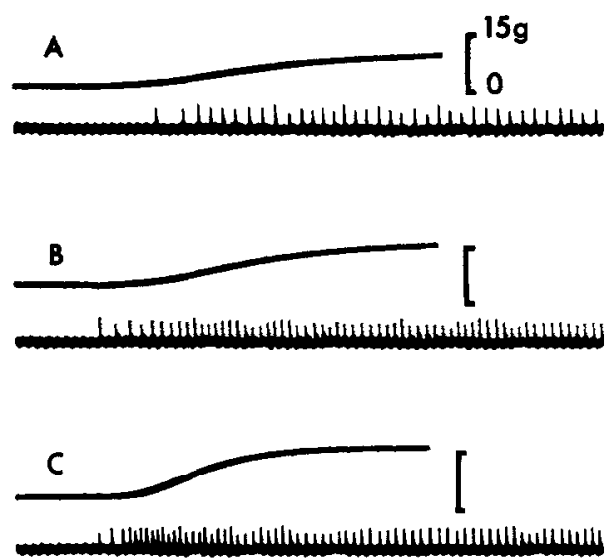

$200 \mu \mathrm{V}$

\section{$.5 \mathrm{SEC}$}

FIG. 3. Discharge patterns of a muscle unit in the thyroarytenoid muscle to pressure. The frequency of discharge of this unit varied directly with the rate of application of the force- $56 / \mathrm{sec}$ with a force increasing at $12 \mathrm{~g} / \mathrm{sec}$ in $\mathrm{B}$ and $84 / \mathrm{sec}$ with a force increasing $40 \mathrm{~g} / \mathrm{sec}$ in $C$, and with the magnitude of the steady force, $44 / \mathrm{sec}$ at $9 \mathrm{~g}$ in $\mathrm{A}$ and $64 / \mathrm{sec}$ at $16 \mathrm{~g}$ in $\mathrm{B}$ and $\mathrm{C}$. The frequency of discharge was determined from the first- and last-quarter second of the records.

Sites initiating proprioceptive discharges are shown in Fig. 2A. Besides displacement of the epiglottis and arytenoid, and thyroid cartilages (arrows in Fig. 2A) responses were recorded on stimulation of sites on the aryepiglottic fold and sites over the epiglottic, transverse arytenoid, thyroarytenoid and lateral cricoarytenoid muscles. The receptive fields were typically long and narrow over the thyroarytenoid muscle and round or oval over the other muscles.

Pressure Units. Figure 4B illustrates a typical response of a pressure unit. Initial frequencies to mechanical stimulation ranged from 20 to 250 impulse/sec. Five units could be excited by light contact, 24 by pressure. and four by puffs of air. Seven units responded to more than one type of stimulation. The response of pressure units to thermal changes were difficult to evaluate because of the rapid adaptation of these units. Pressure units were generally unresponsive to the test solutions. Two units discharged to water, one to $0.5 \mathrm{M}$ sodium chloride, and four to alcohol. Latencies to discharge and recovery times with alcohol were longer for these receptors than for the tactile receptors. The pressure units were usually silent; one was found linked to respiration. Pressure units adapted to one- 

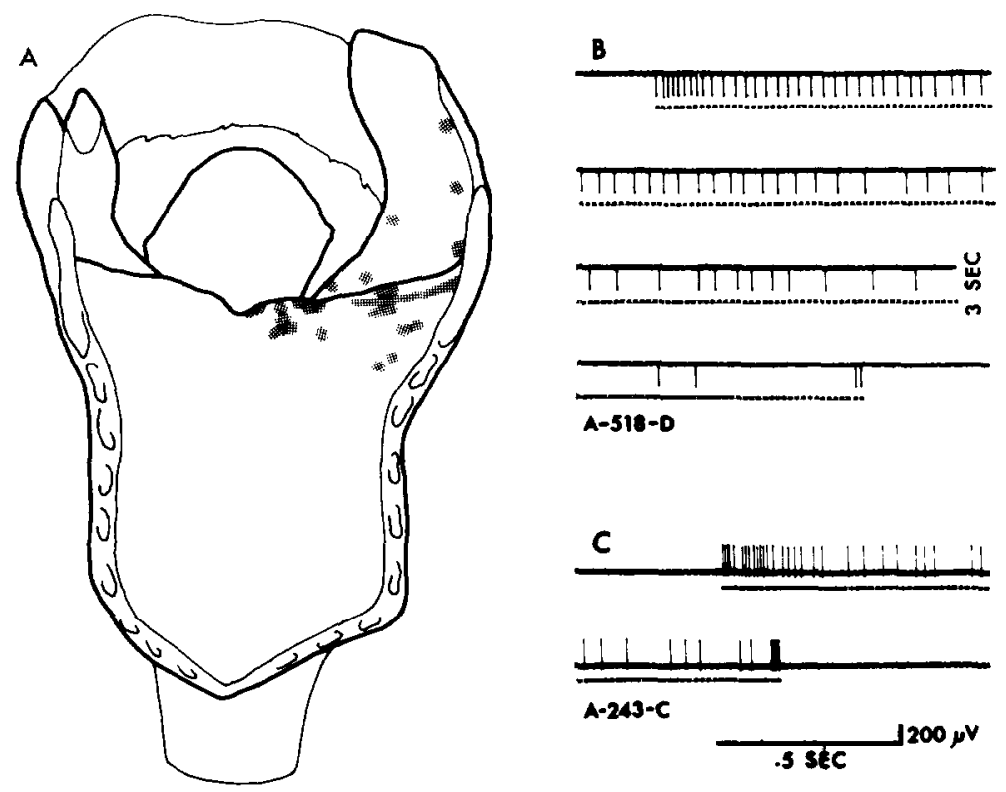

FIG. 4. Receptor fields of pressure units (A) and discharge patterns of two typical units to sustained pressure (indicated by the broken line). The pressure unit in $\mathrm{B}$, lying on the epiglottis, adapted from $42 / \mathrm{impulse} / \mathrm{sec}$ to six impulse/sec over $6.75 \mathrm{sec}$. The unit in $\mathrm{C}$, also on the epiglottis, discharged as the stimulus was removed. Three seconds of the recording has been removed from $B$; recording $C$ is continuous.

half their initial frequency within $0.5-1.6 \mathrm{sec}$. Discharges adapted to zero after $2.5-7 \mathrm{sec}$. Ten pressure units demonstrated a discharge as the mechanical stimulus was removed. Figurc $4 \mathrm{C}$ illustratcs a typical example. The receptive fields for the pressure units which were found over the arytenoid cartilage, the thyroarytenoid and cricoarytenoid muscles, and laryngeal face of the cpiglottis are mapped in Fig. 4A.

Tactile Units. Sixty-two units were excited by light contact (ox hairs or forces less than $0.3 \mathrm{~g}$ ), 97 units by pressure (probe or forces greater than $0.3 \mathrm{~g}$ ), one unit by displacement and 15 units by puffs of air. Not all units were tested to all types of stimulation; 23 units, however, were found which responded to more than one type. The frequency of discharge of tactile units was clevated by cold isotonic saline in nine cases, depressed in one case, and not altered in 17 others. Hot isotonic saline raised the frequency of discharge in one case but did not alter the frequency in the remaining eight cascs tested. Tactile receptors frequently responded to water stimulation. Of 100 units tested, 74 discharged to water while 26 did not. Figure 5C illustrates a typical response to water. The discharge frequency to isotonic saline applicd in the same manner was always much lower. The tactile receptors which responded to water also responded to 

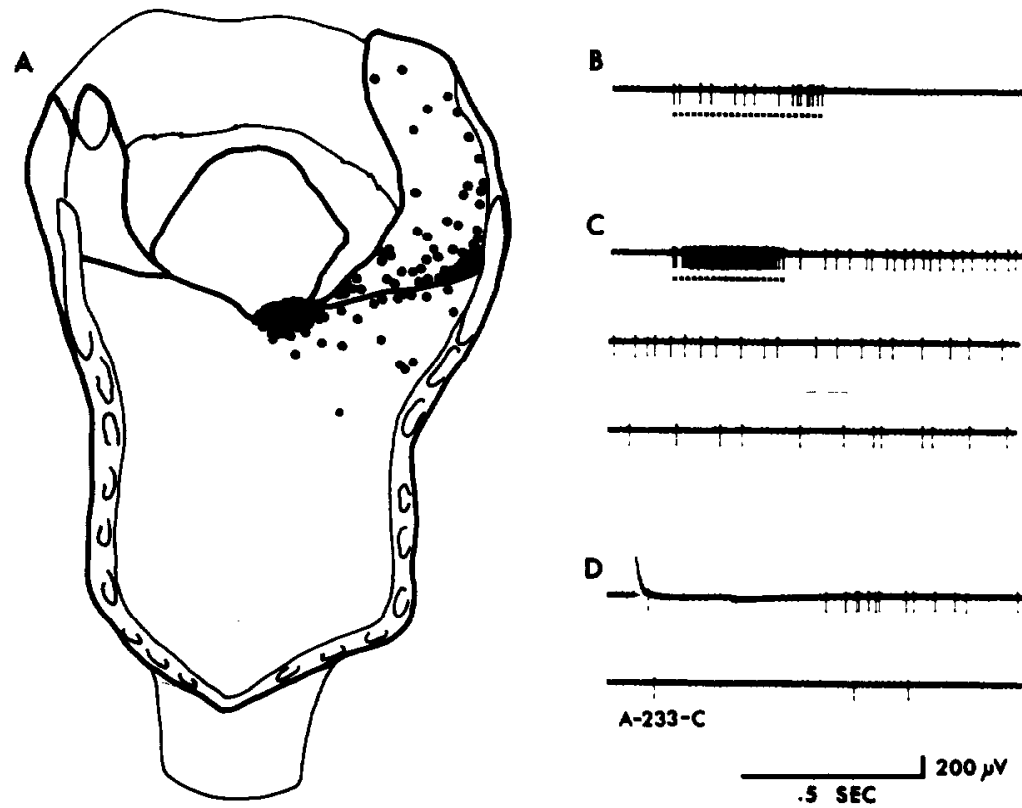

FIG. 5. Points initiating tactile responses (A) and discharge patterns of a typical tactile unit over the thyroarytenoid muscle to: $B$, light contact; $C$, pressure; and $D$, water. Contact with a tiny brush resulted in a discharge (B) of $32 / \mathrm{sec}$. A stronger force applied a few seconds later with a plastic probe to the same site for approximately $0.25 \mathrm{sec}$ elicited a burst of $230 / \mathrm{sec}$ followed by a postdischarge which adapted to $0 / \mathrm{sec}$ in approximately $6 \mathrm{sec}(\mathrm{C})$. The same unit discharged initially at a frequency of $24 / \mathrm{sec}, 0.5 \mathrm{sec}$ after a drop of water had been dropped over the receptor field (D). The broken line in $\mathrm{B}$ and $\mathrm{C}$ indicates the duration of the stimulus: the artifact in $\mathrm{D}$ indicates the moment of contact of the drop of water. Records are continuous in $\mathrm{C}$ and $\mathrm{D}$.

alcohol and acctic acid. Tactile units adapted more slowly to alcohol than to water. However, these receptors, when stimulated by alcohol, frequently discharged at high frequency for several seconds, and then suddenly ceased firing. Irrigation of the receptive field with $0.2 \mathrm{M}$ saline restored the tactile receptor's responsivity after $1-3 \mathrm{~min}$. Tactile receptors were unresponsive to mildly hypertonic sodium chloride solutions and to quinine hydrochloride or sucrose in Ringer's solution. Tactile units were readily anesthetized with topically applied local anesthetic.

Of 95 tactile units for which the resting discharge characteristics were noted, 54 were silent, four were in phase with respiration, and 37 werc tonic. A tonic discharge from a tactile unit was always more irregular than that of a proprioceptive unit and at low frequencies fired very erratically.

Excitation of tactile units would elicit a burst of impulses from 20 to 
$500 / \mathrm{sec}$. Light contact elicited the burst of $32 \mathrm{impulse} / \mathrm{sec}$ in the typical unit shown in Fig. 5B. Pressure elicited a burst of $230 \mathrm{impulse} / \mathrm{sec}$ in the same unit (Fig. 5C) with a postdischarge lasting approximately $6 \mathrm{sec}$. Postdischarges of tactile units ranged from 0.5 to $15 \mathrm{sec}$. As in proprioceptive units the rate of application as well as the magnitude of the stimulus force determined the frequency of discharge in the tactile unit. Records A, B, and C of Fig. 6 illustrate the relationship of threshold for discharge and frequency of discharge to rate of application of the force. In $\mathrm{A}$ the unit commenced discharging at a pressure of $0.12 \mathrm{~g}$ at $36 \mathrm{impulse} / \mathrm{sec}$ when the application was $0.07 \mathrm{~g} / \mathrm{sec}$; in $\mathrm{B}$ at $0.1 \mathrm{~g}$ at 76 impulse/sec when the application was $0.2 \mathrm{~g} / \mathrm{sec}$; and in $\mathrm{C}$ at $0.09 \mathrm{~g}$ at $92 \mathrm{impulse} / \mathrm{sec}$ when the application was $.6 \mathrm{~g} / \mathrm{sec}$. This same unit discharged at $24 \mathrm{impulse} / \mathrm{sec}$ with a steady force of $0.1 \mathrm{~g}$, at $40 \mathrm{impulse} / \mathrm{sec}$ with $0.15 \mathrm{~g}$ and at 80 impulse/ $\mathrm{sec}$ with a force of $0.2 \mathrm{~g}$. Tactile receptors were slow to adapt unless the unit was firing at low frequencies. The unit in Fig. 6 showed no adaptation. when excited as long as three seconds by a force of approximately $0.20 \mathrm{~g}$.
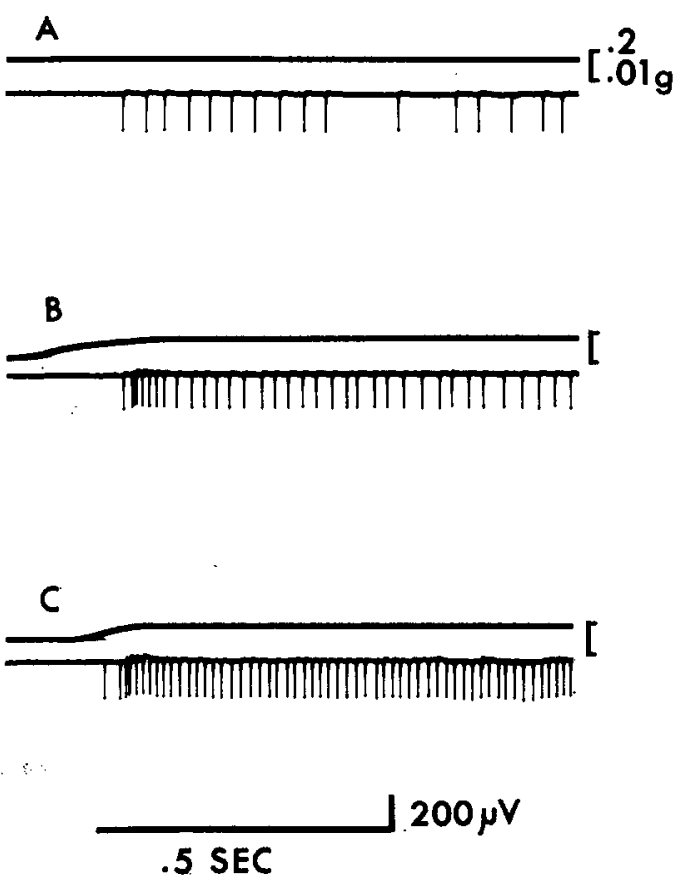

FIG. 6. Discharge patterns of a tactile unit over the arytenoid cartilage to increasing and sustained forces of less than $0.3 \mathrm{~g}$. With stimulus forces increasing at 0.07 $\mathrm{g} / \mathrm{sec}$ in $\mathrm{A}, 0.2 \mathrm{~g} / \mathrm{sec}$ in $\mathrm{B}$ and $0.6 \mathrm{~g} / \mathrm{sec}$ in $\mathrm{C}$ the initial frequencies were 36,76 , and 92 impulse/sec. With steady forces of $0.1 \mathrm{~g}$ in $\mathrm{A}, 0.15 \mathrm{~g}$ in $\mathrm{B}$, and $0.2 \mathrm{~g}$ in $\mathrm{C}$ the unit discharged at frequencies of 24,40 , and $80 \mathrm{impulse} / \mathrm{sec}$. The rate of application of the force as well as its magnitude determines the frequency of discharge. 
Points from which tactile responses with postdischarges were elicited are indicated in Fig. 5A. The fields associated with these points ranged from 2 to $5 \mathrm{~mm}$ in diameter. The tactile receptors were found in the mucosa overlying the arytenoid cartilages, the vocal folds, and the epiglottis. The receptors are most concentrated over the arytenoid cartilage and the laryngeal surface of the base of the epiglottis. The pharyngeal surface of the epiglottis was not examined.

Water Units. Eighty-seven units were identified which discharged to water. Figures 5D, 7B, and 7D illustrate typical responses of water units. Seventy-four of these water units could also be classified as tactile units. Sixty-five units responded to light contact, three to pressure, one to displacement, and eight to puffs of air. Three units responded to more than one mechanical stimulus. Three units were found which could be activated only by water. All water units tested discharged to alcohol and acetic acid. Typical responses of water units to alcohol and acetic acid are illustrated in records $\mathrm{C}$ and $\mathrm{E}$ of Fig. 7. Alcohol always enhanced the response to water. The response of water units to acetic acid in Ringer's was always
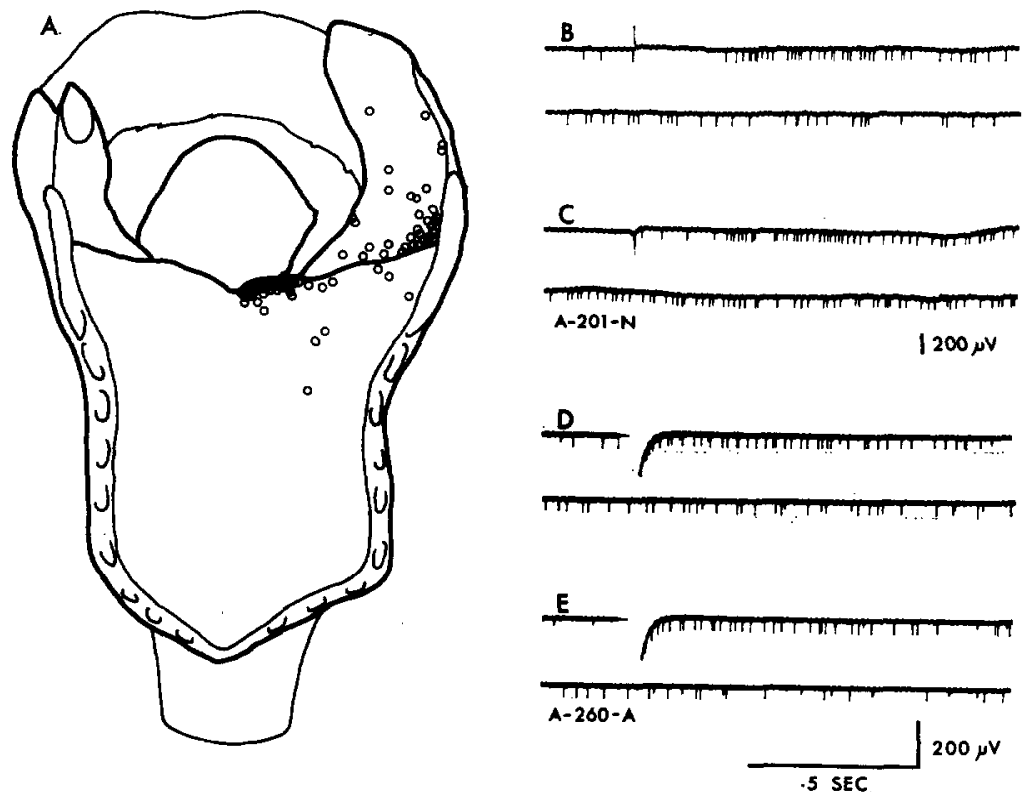

FIG. 7. Distribution of centers of fields (A) and typical responses of water units to water ( $B$ and $D), 4.3 \mathrm{M}$ ethanol in water (C) and $0.2 \mathrm{M}$ acetic acid in Ringer's solution (E). The application of the water or solution was signaled by the artifact in each record. In the first unit the initial frequency to water stimulation was 42 impulse/sec (B) and to alcohol stimulation, $52 \mathrm{impulse} / \mathrm{sec}$ (C). In the second unit the initial frequency to water was 40 impulse/sec (D) and $32 / \mathrm{sec}$ to acid stimulation (E). Records are continuous in B, C, D, and E. 
less than that to water. Water units did not discharge to mildly hypertonic sodium chloride solutions nor to quinine hydrochloride or to sucrose prepared in Ringer's solution. Aqueous solutions of sucrose readily excited water units.

Of 47 water units for which the resting discharge characteristics were noted, 21 were silent, one was phasic, and 25 were tonic. A tonic discharge was always irregular and of low frequency (see frequency values at 0.2 and $0.5 \mathrm{M}$ sodium chloride in Fig. 8 ).

The water unit's response to water was seen after latencies up to $0.6 \mathrm{sec}$, as illustrated in Fig 5. Initial frequencies of discharge ranged from 10 impulse/sec to 184 impulse/sec. Adaptation, which occurred in all water

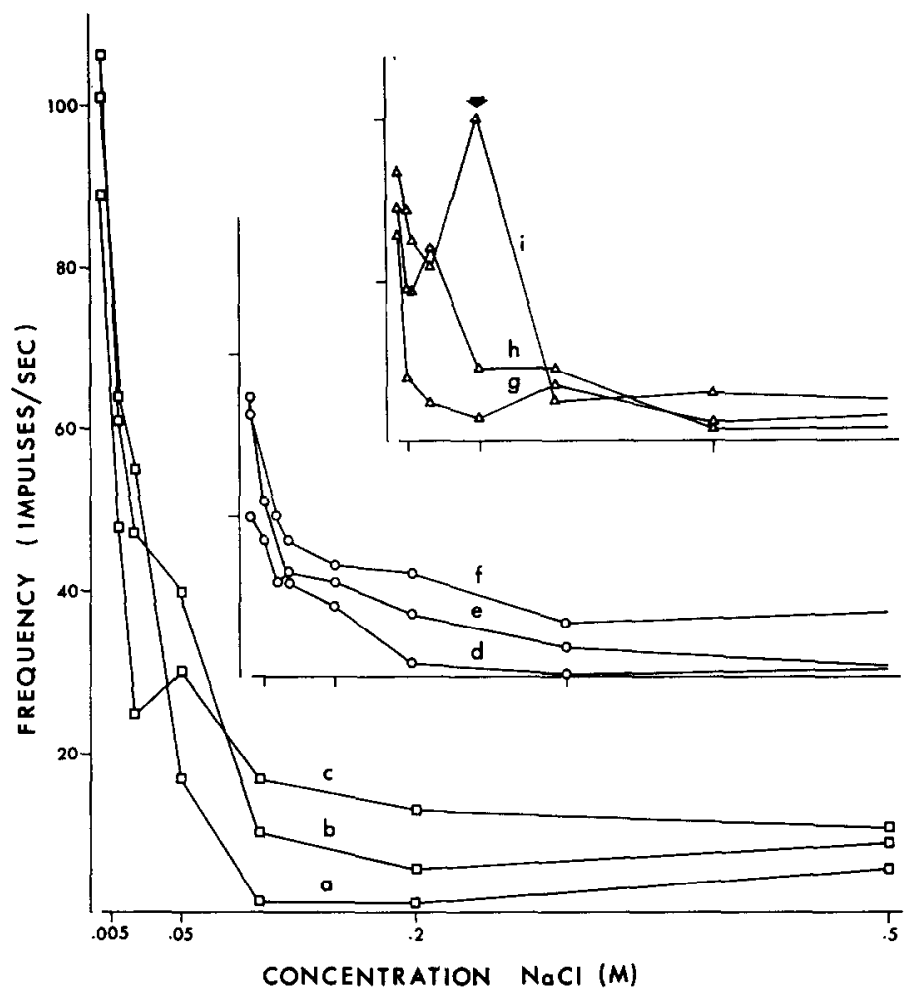

FIG. 8. Frequency response curves of nine typical water units to $\mathrm{NaCl}$ solutions of varied concentration. The solutions were dribbled over the receptor fields after an isotonic saline rinse. Curves $\Delta \longrightarrow \Delta$ were recorded from animals anesthetized with sodium pentobarbital, curves $\bigcirc-O$ were recorded from decerebrate animals, and curves $\square-\square$ from animals anesthetized with choralose. The initial frequencies of discharge were highest for the chloralose animals. The high frequency of discharge of a unit to $0.05 \mathrm{M} \mathrm{NaC1}$ (indicated by the arrow) was due to facilitation by preceding tactile stimulation. Each point represents the number of impulses during the first second of discharge. Abscissa and ordinate units are consistent. 
units, was rapid during the first few seconds. A sporadic discharge of approximately 10 impulse/sec would ensue for several seconds after the rapid adaptation. The frequency response curves of nine typical water units to sodium chloride solutions of varied concentration are graphed in Fig. 8. The initial frequencies of water units in the chloralose preparations were noticably higher than in the other preparations. The units $a, b$, and $c$ in Fig. 8 with initial frequencies of above 80 impulse/sec, were typical of those from animals anesthetized with chloralose. Initial frequencies of units from animals anesthetized with nembutal lie below 60 impulse/sec (Fig. $8 \mathrm{~g}$, h, and i). Initial frequencies of water units from decerebrate animals ranged from 20 to 90 impulse/sec (Fig. $8 \mathrm{~d}$, e, and f). The response of a unit to a test solution depended on the concentration of the solution and the previous experience of the receptor. The response was enhanced by previous mechanical stimulation or by a previsous test solution of higher tonicity. The high-frequency response of unit $i$ in Fig 8 to $0.05 \mathrm{M}$ sodium chloride solution was due to accidental contact of mucosa shortly before application of the solution. Application of a test solution with a concentration higher than that of the solution immediately preceding it (e.g., $0.5 \mathrm{M}$ sodium chloride solution preceding $0.005 \mathrm{M}$ sodium chloride solution) resulted in an augmented response. Application of a test solution with a tonicity close to that of the preceding solution (e.g., $0.005 \mathrm{~m}$ sodium chloride preceding the application of water) resulted in a reduced response. Thoroughly rinsing with isotonic saline between test solutions was imperative for respectable response curves. Tonically active water units and water units which had not fully adapted after excitation by water were supressed by the application of 0.2 or $0.5 \mathrm{~m}$ solutions of sodium chloride.

Centers of the fields excited by water are mapped in Fig. 7A. The water receptors are distributed in the mucosa overlying the arytenoid cartilages, vocal folds, and the epiglottis in the same densities as the tactile receptors.

Hybrid Units. Fourteen units intermediate between a tactile and proprioceptive unit were recorded in the four animals anesthetized with alpha chloralose. One unit was excited by light contact, 13 by pressure, one by displacement, and one by puffs of air. None was responsive to water. All those tested were excited by alcohol but not by any of the other test solutions. Latencies for the alcohol effect were longer than for tactile units: one did not respond until $40 \mathrm{sec}$ after the alcohol was applied. All units were tonically active. When activated with a probe or by displacement of the epiglottis or arytenoid cartilages all the hybrid units discharged at tactile frequencies (i.e., up to $500 \mathrm{impulse} / \mathrm{sec}$ ), did not adapt, and displayed a "silent period" when the stimulus was removed. Figure 9 demonstrates a typical discharge pattern. The fields of the hybrid units lay over the epiglottis, the thyroarytenoid muscle, and the cricoarytenoid muscle. 


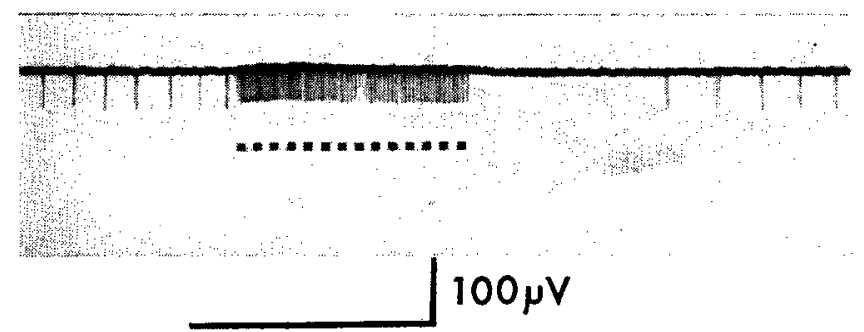

\section{.25 SEC}

FIG. 9. Discharge pattern of a typical hybrid unit whose receptor field was located on the epiglottis. The cat had been anesthetized 5 hours previously with chloralose. This unit discharged at 328 impulse/sec during pressure stimulation (indicated by the broken line), ceased firing for $0.2 \mathrm{sec}$ and then resumed tonic firing.

Other Units. Two units responded to moving water or test solutions as well as to mechanical stimulation. Two other units responded only to moving water or test solutions. One unit would discharge to moving water but not to moving isotonic saline nor to static water or isotonic saline. The second unit would discharge to moving water or any of the test saline solutions. No receptors specifically responsive to sodium chloride, sucrose or quinine hydrochloride in the concentrations specified were found in the cat's larynx.

Units were frequently found which appeared during swallowing. They could not be excited by mechanical stimulation of any of the muscles on the inner surface of the larynx.

\section{Discussion}

A classification system of laryngeal receptors on the basis of stimulus properties, nature of the discharge, or size and distribution of the receptive fields is likely to be both artificial and arbitrary. Many units defy strict classification suggesting that categories such as touch, pressure, displacement, and water are inadequate in defining the sensory repertoire of the larynx. Even among the four chief types of receptors, representing $60 \%$ of the units investigated, there is variability-occasionally a pressure unit may respond to water, a tactile unit may show an off discharge, or a pressure field may resemble a muscle proprioceptive field. Among the remaining $40 \%$ of units, gradations between the chief types is frequently observed. For example, the hybrid units in the chloralose preparations show characteristics of both tactile and proprioceptive units. Superior laryngeal units are more accurately characterized as a spectrum of units with gradations rather than categories of stimulus sensitivity and discharge patterns. Similar gradations in receptor response are also characteristic of receptors 
in the trachea (38) and the skin of the cat (15). Laryngeal units also show variability in their discharge patterns, particularly when discharging spontaneously. Both tactile and proprioceptive units show a variability in "resting" states--units were found which were silent, tonic, or in phase with respiration. These observations agree with those of Sampson and Eyzaguirre (33) for their touch receptors and deep mechanoreceptors. The background discharge of tactile units was more random than that of proprioceptive units. The mean interval for a typical tactile receptor was found to be $251.1 \mathrm{msec} \pm 42.7 \mathrm{SD}$. The mean interval for a typical proprioceptive unit was found to be $44.6 \mathrm{msec} \pm 6.1 \mathrm{SD}$. The tactile system which is characterized by considerably more noise than the proprioceptive system may be more important as an alerting system than a monitoring one. The irregular pattern of spontaneous discharges from tactile units may be due to the interaction of action potentials arising from different terminals supplied by the same afferent fiber as Zotterman (40) suggested for warm receptors and Adrian and Zotterman (3) suggested for touch and pressure receptors. Laryngeal mechanoreceptors also show spontaneous shifts from one pattern of resting discharge to another. Similar fluctuations in threshold were described by Lindblom (22) for cutaneous receptors in amphibians.

Laryngeal mechanoreceptors appear to behave in a confusing manner to temperature: some units show an increase in frequency to a thermal stimulus, others a fall and still others no change. A decrease in frequency of discharge in proprioceptive units was most frequently observed with a decrease in temperature as previously reported by Andrew (4) and Sampson and Eyzaguirre (33). Increases in rate of discharge of tactile units to decreases in temperature are more frequent as observed by Sampson and Eyzaguirre (33). These investigators reported that the touch receptors have resting frequency optima at specific temperatures and that touch units show a wide range of these frequency optima. Frequencies fall off from the optima at lower and higher temperatures. Sampson and Eyzaguirre's "blocking" may represent a fall in frequency to zero at the upper and lower ends of the frequency response ranges of these receptors. These data suggests that the frequency response curve for laryngeal touch receptors would resemble those of the mechanoreceptors of the cat's tongue innervated by medium-sized fibers, i.e., $8-10 \mu$ (13). Fibers of this size make up a significant part of the superior laryngeal population $(27,19)$.

Proprioceptive and Pressure Units. Since water and light contact adequate stimuli for the initiation of swallowing and coughing from the larynx, are usually ineffective in exciting proprioceptive and pressure units, it is unlikcly that their receptors play a role in the initiation of these 
reflexes. Unit discharges initiated from sites exclusively over laryngeal muscles and frequently modified by thermal changes and alcohol strongly suggest that the discharges arise from muscle receptors and not from indirect excitation of perichondrial and articular receptors. In agreement with the findings of Sumi (35), the proprioceptors were refractory to topical anesthetics indicating that they lie deep to the tactile receptors. The muscles receptors are probably not spindles (10). The failure of Andrew (5), Paulsen (30) and Mårtensson (23) to find units firing to stretch in the intrinsic muscles of the larynx of the rat and the dog suggest that length sensitive endings are absent. Stretch was not found to be an effective stimulus in the cat. Increased frequencies of discharge of proprioceptive units were not seen with asphyxiation as described for the stretch receptors in limb muscles $(24,29)$ nor with neuromuscular blocking agents $(14,33)$ as demonstrated for muscle spindles (11). Although muscle receptors are present in the laryngeal muscles of the cat, the more important proprioceptive mechanism in the larynx is likely that of the position receptors (16). The histologic studies of Andrew (4) Yankovskaya (39) and Kirchener and Wyke (16) attest to the richness of the perichondrial and articular innervation in mammals.

Tactile and Water Units. Since the tactile and water units are the only ones excited by the adequate stimuli for swallowing and coughing it must be their receptors which give rise to these reflexes. Since these units are excited by minimal mechanical and water stimulation exclusively, show the shortest latencies to stimulation and are most influenced by alcohol and topical anesthetics their receptors are likely the most superficial. Since the laryngeal epithelium is supplied only with free endings and taste buds $(9,12,28,31,32,36)$, these receptors are probably free endings. Their chemoresponses and distribution are unlike those of the taste buds.

Tactile units of the larynx are rapidly adapting to weak mechanical stimuli (e.g., stream of air over the receptor field) and slowly adapting to strong stimuli (e.g., pressure). Is it possible that these receptors use frequency for coding over a slowly adapting range and use the time derivative of frequency for coding over a rapidly adapting range? Adrian (1) showed that the receptors of the cat toe pad adapt rapidly to forces less than $23 \mathrm{~g}$ and very slowly to forces greater than $43 \mathrm{~g}$. Nonadapting discharges and postdischarges in cutaneous and corneal receptors have been assigned the role of pain mediation $(2,20)$. The high-frequency burst in tactile units with a postdischarge elicited with pressure may represent painful stimulations.

The discharge of water units in the larynx, as in the tongue of the cat $(21,41)$, is neither a mechanical nor an osmotic effect. Isotonic saline does 
not excite these receptors, whereas isotonic sucrose in distilled water does, but in Ringer's solution does not. The cat has few if any receptors for sweetness $(21,41)$. The water response is not due to trace amounts of calcium $(6,20)$, since the calcium concentration of the distilled deionized water used in these studies was less than $3 \times 10^{-7} \mathrm{M}$. The water response has been accredited to withdrawal of anions $(7,21)$ or withdrawal of cations $(17,18)$ from the receptor site. The frequency-response curves of water units in the larynx to varying concentrations of sodium chloride, calcium chloride, and sodium acetate in water did not, however, clarify the mechanism of excitation. Since $75 \%$ of the tactile units were also water sensitive, these units are not modality specific. Sensory units supplying the cat's cornea (20) tongue (13) and skin (15) have also shown to be multimodal. For the laryngeal tactile units sensitive to water, mechanical stimulation facilitates the water response (Fig. 8). Flow, which tended to enhance the water response, is not essential as in tongue water units (7). Laryngeal tactile units are sensitive to air flow (35) or perhaps more accurately to mucous movement resulting from changes in air flow. Mechanical facilitation of the water response illustrates the potential hazard of applying test solutions to mechanosensitive receptors with a brush or swab.

The question arises of whether the mechano- and chemotransducer sites on the sensory terminals of these bimodal units are common or separate. Some light is shed on the question by the effects of anesthetics on these units. Chloralose increased the maximum discharge rates of water receptors whereas Nembutal decreased the rates (Fig. 8). Chloralose and Nembutal injected in anesthetic doses into decerebrated cats did not alter the discharge characteristics of tactile units to mechanical stimulation. The chemotransducer is sensitive to the two anesthetic agents while the mechanotransducer is not. These observations suggest that the transducer sites are separate.

If the sensory units giving rise to swallowing and coughing are common and are excited by chemical and mechanical stimuli what are the discharge characteristics which initiate each reflex? Frequency, adaptation, and patterning are usually considered the most significant parameters of sensory discharges. Since the frequencies and adaptation rates for the units discharging to touch and water are similar, these would not appear to be meaningful parameters. Electrical stimulation of the whole SLN however, is most effective in eliciting swallowing at $30 / \mathrm{sec}$ and in eliciting coughing at higher frequencies. Doty (8) showed that at the optimal frequency of $30 / \mathrm{sec}$ for swallow elicitation there was considerable freedom of patterning possible. Pattern of discharge does not appear to be important. The pattern 
of units discharging, the degree of activity of units in this mosaic or perhaps the sequence of activity of units, parameters difficult to evaluate, may hold the key.

\section{References}

1. Adrian, E. D. 1926. The impulses produced by sensory nerve-endings. Part 4: Impulses from pain receptors. J. Physiol. London $62: 33-51$.

2. Adrian, E. D. 1928. "The Basis of Sensation." Christophers, London.

3. Adrian, E. D., and Y. Zotrerman. 1926. The impulses produced by sensory nerve endings. III. Impulses set up by touch and pressure. J. Physiol. London 61: 465-483,

4. Andrew, B. L. 1954. Propriception at the joint of the epiglottis of the rat. $J$. Physiol. London 126 : 507-523.

5. ANDREW, B. L. 1956. A functional analysis of the myelinated fibers of the superior laryngeal nerve of the rat. J. Physiol. London $133: 420-432$.

6. Casella, C., and G. Rapuzzi. 1957. Azione dell acqua del $\mathrm{CaCl}_{2}$ e del $\mathrm{NaCl}$ sui ricettori lingual nella Rana. Arch. Sci. Biol. Bologna 41: 191-203.

7. Cohen, M. J., S. Hagiwara, ann Y. Zotterman. 1955. The response spectrum of taste fibers in the cat: a single fiber analysis. Acta Physiol. Scand. $33: 316-332$.

8. Dоту, R. W. 1951. Influence of stimulus pattern on reflex deglutition. Am. J. Physiol. 166: 142-158.

9. Gracheva, M. S. 1950. Reflexogenic zones of the larynx. V'estn. Oto-Rino.Laringol. 6 : 12-17. (Russian).

10. Gracheva, M. S. 1963. Sensory innervation of the locomotor apparatus of the larynx. Fcderation Proc. Trans. Suppl. 22: T1120-T1123.

11. Granit, R., S. Skoglund, and S. TheslefF. 1953. Activation of muscle spindles by succinylcholine and decamethonium. The effects of curare. Acta Physiol. Scand. 28: 134-151.

12. Hatakeyama, S. 1960. Histological study on the nerve distribution in the larynx in cat. Arch. Histol. Japan $19: 369-389$.

13. Hensel, H., and Y. Zottriman. 1951. The response of mechann-receptors to thermal stimulation. J. Physiol. London 115: 16-24.

14 Hirose, H. 1961 Afferent impulses in the recurrent laryngeal nerve in the cat. Laryngoscope 71: 1196-1206.

15. Hunt, C. C., and A. K. McIntire. 1960 An analysis of fibre diameter and receptor characteristics of myelinated cutaneous afferent fibres in cat. $J$. Physiol. London 153: 99-112.

16. Kirchener, J. A., and B. Wyke. 1964. Innervation of laryngeal joints and laryngeal reflexes. Nature 201: 506.

17. KoKetsu, K. and K. Kimura. 1953. Effect of some salt ions upon chemoreceptors in the mucous membrane of a frog's palate. Kyushu Mem. Med. Sci. 3: 233-241.

18. Kusano, K., and M. Sato. 1957. Properties of fungiform papillae in frog's tongue. Japan. J. Physiol. 7: 324-338.

19. Lam, R. L., AND J. H. OGURA. 1952. An afferent representation of the larynx in the cerebellum. Laryngoscope 62: 486-495.

20. LeLE, P. P., AND G. WedDEL.t. 1959. Sensory nerves of the cornea and cutaneous sensibility. Exptl. Neurol. 1: 334-359.

21. Liljestrand, G., And Y. Zotterman. 1954. The waler taste in mammals. Acta. Physiol. Scand. 32: 291-303. 
22. Lindelom, U. 1958. Excitability and functional organization within a peripheral tactile unit. Acta. Physiol. Scand. Suppl. 15344 : 1-84.

23. MÅrTensSON, A. 1963. Reflex responses and recurrent discharges evoked by stimulation of laryngeal nerves. Acta Physiol. Scand. 57: 248-269.

24. Matthews, B. H. C. 1933. Nerve endings in mammalian muscle. J. Physiol. London 78: 1-53.

25. Negus, V. E. 1949. "The Comparative Anatomy and Physiology of the Larynx." Heinemann, London.

26. Nomura, H., and S. Sakada. 1965. On the "water response" of frog's tongue. Japan. J. Physiol. 15: 433-443.

27. OdachI, R. 1936. Studien und Untersuchungen über die Kehlkopfnervenfasern. Japan. J. Med Sci., I. Anat. 6: 153-206.

28. OPPEL, A. 1900. "Lehrbuch der vergleichenden mikroskopischen Anatomie der Wirbeltiere," Vol. 3, Teil, Gustav Fischer, Jena.

29. Paintal, A. S. 1959. Facilitation and depression of muscle stretch receptors by repetitive antidromic stimulation, adrenaline and asphyxia. J. Physiol. London. 148: 252-266.

30. Paulsen, K. 1958. Utber die Bedeutung von Muskelspindeln und Schleimhautreceptoren bei der Phonation. Arch. Ohren Nasen u. Kchlk. Heilk. 173: 500 503.

31. Plosch ко, A. 1897. Die Nervenendigungen und Ganglien der Respirationsorgane Anat. Anz. 13: 12-22.

32. Retzius. G. 1893. "Biologische Untersuchungen," Vol. 4, New Series, Samson and Wallin, Stockholm.

33. Sampson, S., and C. Eyzaguirre. 1964. Some functional characteristics of mechanoreceptors in the larynx of the cat. J. Neurophysiol. 27: 464-480.

34. Storey, A. T. 1968. Laryngeal initiation of swallowing. Exptl. Neurol. 20: 359365.

35. Sumr, T. 1959. Afferent impulses in the superior larygeal nerve fibers and the mechanism of their generation. Seitai-no-Kagaku 10:30-38. (Japanese).

36. Voloshchenko, A. A. 1960 . On the question of sensory innervation of the epiglottis of animals. Arkh. Anat. Gistol. i Embriol. 39: 93-96. (Russian).

37. Widdicombe, J. G. 1954. Respiratory reflexes from the trachea and bronchi of the cat. J. Physiol. London. 123: 55-70.

38. Widprcomse, J. G. 1954. Receptors in the trachea and bronchi of the cat. $J$. Physiol. London 123: 71-104.

39. Yankovskaya, N. F. 1959. The receptor innervation of the perichondrium of the laryngeal cartilages. Arkh. Anat. Gistol. i Embriol. 37: 71-84. (Russian).

40. Zotterman, Y. 1953. Special senses: thermal receptors. Ann. Rev. Physiol. 15: $357-372$.

41. Zotterman, Y. 1961. Studies in the neural mechanism of taste. pp. 205-216. In "Sensory Communication," W. A. Rosenblith [ed.]. Wiley, New York. 